Abstracta Iranica Abstracta Iranica

Revue bibliographique pour le domaine irano-aryen

Volume 27 | 2006

Comptes rendus des publications de 2004

" The Rebound Theater State: The Politics of the Safavid Camel Sacrifice Rituals, 1598-1695 C.E. ». Iranian Studies, 37/3 (2004), pp. 451-478.

Jean Calmard

CpenEdition

Journals

Édition électronique

URL : http://journals.openedition.org/abstractairanica/5994

DOI : 10.4000/abstractairanica.5994

ISSN : 1961-960X

Éditeur :

CNRS (UMR 7528 Mondes iraniens et indiens), Éditions de l'IFRI

Édition imprimée

Date de publication : 15 mai 2006

ISSN : 0240-8910

Référence électronique

Jean Calmard, " «The Rebound Theater State: The Politics of the Safavid Camel Sacrifice Rituals,

1598-1695 C.E. ». Iranian Studies, 37/3 (2004), pp. 451-478. », Abstracta Iranica [En ligne], Volume 27 |

2006, document 190, mis en ligne le 02 janvier 2007, consulté le 25 septembre 2020. URL : http://

journals.openedition.org/abstractairanica/5994 ; DOI : https://doi.org/10.4000/abstractairanica.5994

Ce document a été généré automatiquement le 25 septembre 2020.

Tous droits réservés 


\title{
"The Rebound Theater State: The Politics of the Safavid Camel Sacrifice Rituals, 1598-1695 C.E. ». Iranian Studies, 37/3 (2004), pp. 451-478.
}

\author{
Jean Calmard
}

En reprenant des versions antérieures de cette étude et une communication à l'Université de Chicago (mai 2003), amplement commentée par des collègues, l'A. revient ici, après bien d'autres, sur les rituels du sacrifice du chameau sous les Safavides. Après avoir réfuté les approches «fonctionnalistes » de divers auteurs (dont nous-même, dans notre article de 1996 qu'il a pu lire en anglais) sur l'utilisation de la religion populaire à des fins politiques, il propose une révision complète de la lecture des témoignages européens et de leur fiabilité, ainsi qu'une recherche des données « ethnographiques» concernant leurs observations. Il se propose de baser de futures analyses sur l'utilisation des théories de divers auteurs modernes (apparemment ignorants des complexités culturelles du monde turco-iranien). Il faudrait tout d'abord se demander pourquoi les Persans ont si peu témoigné sur leur propre culture (leur intérêt se situant ailleurs). Quant à l'utilisation des ressorts émotifs de la religion populaire, ils ont été partout et de tout temps pain béni pour les gens de pouvoir. Faisant feu de tout bois, ils seraient bien surpris que l'on puisse voir dans leur attitude une quelconque interprétation « fonctionnaliste ». On peut aussi se demander si l'A. a la capacité d'entreprendre la vaste « révision » qu'il se propose. Peut-il lire le français ? Il reproduit le titre de notre article sur «Les rituels shiites et la (sic) pouvoir... » (1993) avec quatre fautes d'orthographe (n. 8). Henri Massé (écrit Messé) est cité d'après une traduction anglaise (n. 22). Que dire de la lecture de Chardin, du Mans, Tavernier etc. Selon lui, l'origine de l'édification de tours de crânes en Iran remonte à l'invasion mongole de 1258 (en fait, des tours de crânes humains, édifiées à Nishâpur en 1221, que 
l'on ne peut comparer aux trophées de crânes d'animaux, souvent observés chez les Safavides, dont il fait mention, p. 475).

INDEX

Thèmes : 4.2.1. Safavides et Qâjârs

nompropre Safavides

\section{AUTEURS}

JEAN CALMARD

CNRS - Paris 